\title{
Control of Breathing in Children with Interstitial Lung Disease
}

\author{
Cl. GAULTIER, ${ }^{(2+)}$ L. PERRET, M. BOULE, G. TOURNIER, AND F. GIRARD \\ Laboratory of Physiology and Pediatric Department [G.T.]. Hôpital TROUSSEAU, 26, Avenue du Dr A. Netter, \\ Paris 75012, France
}

\begin{abstract}
Summary
Control of breathing at rest was studied in 14 children (4-16 years old) with interstitial lung disease (ILD). Four of them were tested several times. Breathing pattern and the mouth occlusion pressure $\left(P_{0.1}\right)$ were measured. Results in ILD children were compared to values in healthy children previously reported. Respiratory frequency and minute ventilation were increased $(P<$ $0.02)$. Inspiratory time $(\mathrm{TI})$ was shortened $(P<0.001)$, the shortening in $\mathrm{Tr}$ being significantly related to the increase in lung elastance (EL). The ratio of $T I$ to the total duration of the respiratory cycle (TI/TTOT) was lowered $(P<0.01)$. Tidal volume (VT) both in $\mathrm{ml}$ and normalized for body weight $(\mathrm{BW})$ was normal. $\mathbf{P}_{0.1}$ was higher than predicted. The increase in $P_{0.1}$ was significantly related to change in arterial $\mathrm{O}_{2}$ pressure $\left(\mathrm{PaO}_{2}\right)$ which was reduced in 10 cases. There was a significant relationship between the increase in $P_{0.1}$ and in $E_{L}$. The increase in mean inspiratory flow $\left(\mathrm{VT}_{\mathrm{BW}} /\right.$ $\mathrm{TI})$ was related to the increase in $\mathrm{EL}_{\mathrm{L}}$. But $\mathrm{VT}_{\mathrm{BW}} / \mathrm{TI}_{\mathrm{I}}$ was not increased as much as $\mathbf{P}_{0.1}$. Consequently the effective inspiratory impedance was enhanced. This high effective inspiratory impedance was related to the increased lung elastance.
\end{abstract}

\section{Speculation}

Increase in the neural drive in ILD children appears to be due to hypoxemia and/or to the increased elastic load. The effects of the elastic load on the control of breathing are probably vagallymediated.

In adults with interstitial lung disease (ILD) increase in respiratory frequency and minute ventilation have been previously observed suggesting an increased inspiratory drive (13). More recently the mouth occlusion pressure generated $0.1 \mathrm{sec}$ after airway occlusion at the end expiratory level $\left(P_{0.1}\right)$ was measured in ILD adults and found enhanced $(2,3,17,18)$. Because $P_{0.1}$ is related to the inspiratory neural drive $(5,21)$, its increase in ILD adults is in agreement with the previous hypothesis (13).

The aim of the present study was to analyze the breathing pattern and to measure $P_{0.1}$ in 14 children with ILD during resting breathing. Changes in control of breathing in ILD children were related to lung mechanics and to pulmonary gas exchange data.

\section{MATERIALS AND METHODS}

Fourteen children with ILD were tested. Their age and weight are reported in Table 1 . Parental consent for each child was obtained. In all the cases the $\mathrm{x}$-ray data were in favor of ILD. The etiology of ILD was based on histologic (eight cases), immunologic (four cases of hypersensitivity pneumonitis) or viral (two cases) findings (Table 1). Four of them were tested several times (No. 1, $4,7,14$, Table 1). In all of them pulmonary function tests were performed. Vital capacity (VC), functional residual capacity (FRC), total pulmonary resistance $\left(R_{L}\right)$, dynamic and/or static lung compliance $(\mathrm{Cr}$.) measured in the tidal volume range, lung transfer factor for co (TLCO) and blood gases were determined, using methods previously described (7). During the same test the latter parameters and control of breathing were measured.

For the study of control of breathing, the children were studied awake in the sitting position. None had received any premedication. They breathed room air with a mouth piece and a nose-clip through a pneumotachograph (Fleish no. 1 for children younger than 8 years, and no. 2 for children older than 8 years). The pneumotachograph was attached to a two-way valve that separated the inspiratory from the expiratory line. Instrumental dead space amounted to $45 \mathrm{ml}$ in the children less than 8 years and 70 $\mathrm{ml}$ for the others.

Breathing pattern was analyzed on at least 10 respiratory cycles under resting breathing conditions in terms of tidal volume (VT), inspiratory and expiratory volume ( $\mathrm{Tr}, \mathrm{TE}$ ), total duration of the respiratory cycle (TTOT) and minute ventilation (VE). Tidal volume was normalized for body weight (BW). The mean inspiratory flow was calculated in terms of $V_{T_{B W}} / T_{I}$.

The mouth occlusion pressure was measured with a pressure transducer (Statham $\pm 50 \mathrm{cmH}_{2} \mathrm{O}$ ). Airway occlusions were performed by inflating a $3-\mathrm{cm}$ long balloon placed on the respiratory line during expiration. The inspiratory line was occluded for $0.3-$ $0.7 \mathrm{sec}$. Great care was taken to avoid any leak around the mouth piece during the occlusions. Occlusions were repeated at least five times at intervals of at least $1 \mathrm{~min}$. In four children (cases no. I, $7,9,14) \mathrm{P}_{(t, 1}$ was also measured after $\mathrm{O}_{2}$ breathing. This was done by connecting a bag of pure oxygen to the inspiratory line. The subjects breathed $\mathrm{O}_{2}$, during two consecutive respiratory cycles. $P_{0.1}$ was measured 8-12 sec after $\mathrm{O}_{2.2}$ inhalation (9).

Results in ILD children were compared to breathing pattern and $P_{0.1}$ values previously reported in healthy children (9). The paired $t$ test was used in order to compare the ILD's values with the predicted ones according to the equation of regression previously reported between each variable and age (9).

\section{RESULTS}

Results of pulmonary function tests expressed as \% of the predicted values are reported in Table 1. In Table 2 the components of breathing pattern and mouth occlusion pressure $\left(P_{0.1}\right)$ are included. It can be seen that respiratory frequency was higher $(P$ $<0.02$ ) (Fig. 1, upper panel), inspiratory time (TI) shorter $(P<$ $0.001)$ (Fig. 1, middle panel), TI/TTOT ratio lower $(P<0.001)$ (Fig. l, lower panel), minute ventilation greater $(P<0.02)$ in ILD than in healthy children (9). Tidal volume was in the normal range, both expressed in absolute values $(\mathrm{ml})$ or normalized for

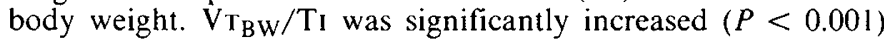
(Fig. 3, upper panel), and $P_{0.1}$ higher than predicted $(P<0.001)$ (Fig. 2). There was a significant relationship between $P_{0.1}$ and both $\dot{\mathrm{V}}_{\mathrm{BW}}(r=0.49, P<0.05)$ and $\mathrm{VT}_{\mathrm{BW}} / \mathrm{TI}_{\mathrm{I}}(r=0.70, P<0.001)$. The ratio of $P_{0,1}$ to $V T_{B W} / T_{I}$, that is the effective inspiratory impedance, was calculated, it was significantly greater than predicted $(P<0.01)$ (Fig. 3, lower panel).

Control of breathing data were compared to changes in lung 
Table 1. Pulmonary function tests ${ }^{1}$

\begin{tabular}{|c|c|c|c|c|c|c|c|c|c|c|c|c|c|}
\hline Case & Sex & $\begin{array}{l}\mathrm{BW} \\
(\mathrm{kg})\end{array}$ & $\begin{array}{l}\text { Age } \\
(\mathrm{yr})\end{array}$ & Diagnosis & $\mathrm{VC}^{3}$ & $\mathrm{FRC}^{3}$ & TLCO $^{3}$ & $\mathrm{RL}^{3}$ & $\mathrm{CL}^{3}$ & $\mathrm{EL}^{3}$ & & $\begin{array}{l}\mathrm{O}_{2} \\
\mathrm{H} \mathrm{Hg})\end{array}$ & $\begin{array}{c}\mathrm{PaCO}_{2} \\
(\mathrm{mmHg})\end{array}$ \\
\hline \multirow[t]{3}{*}{1} & $\mathrm{M}$ & 17 & 5 & LIP:2 & & 70 & 33 & 111 & 36 & 276 & 82 & (97) & 31 \\
\hline & & 17 & 5.6 & & & 81 & 40 & 86 & 22 & 380 & 80 & $(90)$ & 36 \\
\hline & & 18.5 & 6 & & & 97 & 51 & 95 & 28 & 353 & 77 & (87) & 35 \\
\hline 2 & $\mathrm{~F}$ & 24 & 6 & HP & & 77 & 59 & 93 & 69 & 145 & 70 & $(80)$ & 34 \\
\hline 3 & $F$ & 20 & 6 & D & & 85 & 76 & 101 & 55 & 182 & 84 & (95) & 30 \\
\hline \multirow[t]{3}{*}{4} & $M$ & 42 & 14.4 & HP & 28 & 83 & 53 & 148 & 23 & 457 & 58 & (63) & 33 \\
\hline & & 42 & 14.6 & & 57 & 94 & 59 & 124 & 59 & 169 & 81 & (87) & 36 \\
\hline & & 48 & 15.3 & & 75 & 88 & 73 & 100 & 69 & 131 & 87 & (94) & 36 \\
\hline 5 & $F$ & 31 & 11 & HP & 70 & 96 & 90 & 107 & 73 & 134 & 98 & (95) & 33 \\
\hline 6 & $\mathrm{~F}$ & 32 & 12 & NPD" & 39 & 88 & 60 & 100 & 22 & 447 & 85 & (91) & 35 \\
\hline \multirow[t]{3}{*}{7} & $M$ & 32 & 12 & $\mathrm{PH}^{2}$ & 66 & 147 & 52 & 176 & 43 & 230 & 82 & (88) & 35 \\
\hline & & 34 & 13 & & 69 & 124 & 59 & 128 & $58^{4}$ & 174 & 83 & (88) & 37 \\
\hline & & 34 & 14 & & 60 & 126 & 52 & 162 & $46^{4}$ & 227 & 79 & (85) & 34 \\
\hline 8 & $\mathrm{~F}$ & 26 & 12 & $\mathrm{NPD}^{2}$ & 78 & 100 & 80 & 105 & $73^{4}$ & 148 & & & \\
\hline 9 & $F$ & 36 & 14 & PVD $^{2}$ & 68 & 87 & 37 & 111 & $38^{4}$ & 262 & 73 & (79) & 34 \\
\hline 10 & $M$ & 17.5 & 7.9 & $\mathrm{NPD}^{2}$ & & 131 & 93 & 132 & $44^{4}$ & 224 & 84 & (91) & 36 \\
\hline 11 & $F$ & 20 & 7.3 & VIP'2 & & 108 & 62 & 104 & 49 & 200 & 86 & (94) & 36 \\
\hline 12 & $M$ & 15.5 & 4.5 & VIP & & 102 & & 97 & 51 & 198 & 92 & (105) & 32 \\
\hline 13 & $F$ & 24 & 9.6 & HP & 86 & 75 & 57 & 126 & $44^{4}$ & 227 & 71 & (77) & 38 \\
\hline \multirow[t]{2}{*}{14} & $\mathrm{~F}$ & 15.5 & 6.6 & VIP' & & 87 & 67 & & 36 & 280 & 80 & (90) & 35 \\
\hline & & 15.5 & 6.8 & & & 78 & & & 31 & 286 & 73 & (83) & 36 \\
\hline
\end{tabular}

'BW, body weight; y, years; LIP, Lymphoid Interstitial Pneumonia; HP, Hypersensitivity Pneumonitis; D, Dermatomyositis; NPD, Nieman Pick's Disease: PVD, Pulmonary vascular disease; VIP, Viral Interstitial Pneumonia; PH, Pulmonary Hemosiderosis.

"Lung biopsy. VC, vital capacity; FRC, functional residual capacity; TLCo, lung transfert for CO; RL, lung resistance; $\mathrm{CL}$, dynamic lung compliance; EI., lung elastance: Pao.: is expressed in absolute terms and as \% of the predicted values in brackets.

As $\%$ of predicted values.

' Static lung compliance.

Table 2. Breathing pattern and mouth occlusion pressure ${ }^{1}$

\begin{tabular}{|c|c|c|c|c|c|c|c|c|c|c|}
\hline \multirow[b]{2}{*}{ Case } & \multirow{2}{*}{ 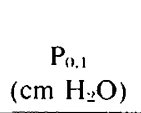 } & \multirow[b]{2}{*}{$(*)$} & \multirow{2}{*}{$\begin{array}{c}\mathbf{f} \\
\left(\mathrm{m}^{-1}\right)\end{array}$} & \multirow{2}{*}{$\begin{array}{l}T_{I} \\
(s)\end{array}$} & \multirow[b]{2}{*}{ Til/Tтот } & \multicolumn{2}{|c|}{$V_{T}$} & \multirow{2}{*}{$\begin{array}{c}\dot{\mathrm{V}} \mathrm{E}_{\mathrm{BW}} \\
\left(\mathrm{ml} \cdot \mathrm{kg}^{-1}\right. \\
\left.\mathrm{m}^{-1}\right)\end{array}$} & \multirow{2}{*}{$\begin{array}{c}\mathrm{VT}_{\mathrm{BW}} / \mathrm{T}_{\mathrm{I}} \\
\left(\mathrm{ml} \cdot \mathrm{s}^{-1}\right. \\
\left.\mathrm{kg}^{-1}\right)\end{array}$} & \multirow{2}{*}{$\begin{array}{c}\mathrm{P}_{0.1} / \mathrm{VT}_{\mathrm{HW}} / \mathrm{TI} \\
\left(\mathrm{cm} \mathrm{H}_{2} \mathrm{O} / \mathrm{ml}\right. \\
\left.\mathrm{kg}^{-1} \cdot \mathrm{s}^{-1}\right)\end{array}$} \\
\hline & & & & & & $(\mathrm{ml})$ & $\left(\mathrm{ml} \cdot \mathrm{kg}^{-1}\right)$ & & & \\
\hline \multirow[t]{3}{*}{1} & 4.5 & & 32 & 0.9 & 0.48 & 206 & 12.2 & 390 & 13.4 & 0.336 \\
\hline & 5.6 & & 43 & 0.6 & 0.40 & 184 & 10.5 & 441 & 19.3 & 0.305 \\
\hline & 8.7 & 6.2 & 38 & 0.6 & 0.37 & 222 & 12 & 456 & 20.7 & 0.420 \\
\hline 2 & 5.2 & & 32 & 0.8 & 0.42 & 225 & 11.7 & 378 & 11.7 & 0.444 \\
\hline 3 & 5.3 & & 38 & 0.8 & 0.47 & 186 & 9.3 & 353 & 12.2 & 0.434 \\
\hline \multirow[t]{3}{*}{4} & 5.5 & & 47 & 0.5 & 0.42 & 272 & 6.5 & 306 & 12.2 & 0.450 \\
\hline & 2.2 & & 23 & 1.1 & 0.42 & 426 & 9.2 & 212 & 8.4 & 0.257 \\
\hline & 2.6 & & 21 & 1.2 & 0.41 & 461 & 9.6 & 202 & 8 & 0.325 \\
\hline 5 & 2.6 & & 24 & 0.9 & 0.37 & 264 & 8.5 & 204 & 9.1 & 0.286 \\
\hline 6 & 5 & & 25 & 0.8 & 0.35 & 275 & 8.6 & 215 & 10.4 & 0.487 \\
\hline \multirow[t]{3}{*}{7} & 2.9 & & 19 & 1.4 & 0.43 & 430 & 13.9 & 264 & 9.9 & 0.298 \\
\hline & 2.6 & 2.3 & 18 & 1.5 & 0.44 & 445 & 13 & 234 & 9 & 0.284 \\
\hline & 2.9 & & 19 & 1.3 & 0.39 & 357 & 10.5 & 189 & 8.3 & 0.280 \\
\hline 8 & 1.9 & & 22 & 1 & 0.37 & 284 & 10.9 & 239 & 10.9 & 0.362 \\
\hline 9 & 3.4 & 2.8 & 21 & 1.1 & 0.39 & 372 & 10.3 & 206 & 9.4 & 0.261 \\
\hline 10 & 3.5 & & 26 & 1.1 & 0.45 & 248 & 14.2 & 368 & 13.5 & 0.332 \\
\hline 11 & 3.2 & & 20 & 1.3 & 0.42 & 243 & 12.2 & 243 & 9.8 & 0.331 \\
\hline 12 & 5.6 & & 36 & 0.7 & 0.44 & 189 & 12.1 & 436 & 16.8 & 0.345 \\
\hline 13 & 3.4 & & 16 & 1.7 & 0.46 & 389 & 16.2 & 259 & 9.5 & 0.316 \\
\hline \multirow[t]{2}{*}{14} & 6.8 & & 46 & 0.5 & 0.42 & 190 & 11.9 & 547 & 21.6 & 0.417 \\
\hline & 9.2 & 8 & 50 & 0.5 & 0.43 & 170 & 11 & 550 & 22 & 0.418 \\
\hline
\end{tabular}

${ }^{1} \mathrm{P}_{0,1}$, mouth occlusion pressure $0.1 \mathrm{~s}$. after the onset of inspiration; $\left({ }^{*}\right) \mathrm{P}_{0,1}$ measured $8-12 \mathrm{sec}$ after the onset of $\mathrm{O}_{2}$ inhalation; $\mathrm{f}$, respiratory frequency; Tr. inspiratory time; $T_{T w}$, total duration of the respiratory cycle; $\mathrm{VT}$, tidal volume; $\mathrm{V}_{\mathrm{HW}}$, $\mathrm{VT}$ normalized for body weight; $\dot{V}_{\mathrm{Hw}}$ : minute ventilation normalized for body weight; and $\mathrm{VT}_{\mathrm{r}} / \mathrm{T}_{1}$, mean inspiratory flow normalized for body weight.

mechanics and to gas exchange abnormalities. In Fig. 4, $\mathrm{PaO}_{2}$ was related to $P_{10.1}$, both expressed as \% of predicted values: the lower was $\mathrm{PaO}_{2}$ the higher was $\mathrm{P}_{0.1},(r=0.57, P<0.01)$. The increase in lung elastance (EL) (Table 1 ), expressed as $\%$ of predicted values was correlated with the increase in $\mathrm{P}_{0.1}(r=0.78, P<0.01)$ for the whole ILD group (Fig. 5, upper panel). In the lower panel of Fig. 5 , only $\mathrm{P}_{0.1}$ 's patients with normal $\mathrm{PaO}_{22}$ and with $\mathrm{P}_{0.1}$ measured after $\mathrm{O}, 2$ breathing (cases 1, 7, 9, 14, Table 2) were taken into account and compared to the corresponding changes in $\mathrm{EL}_{\mathrm{L}}(r=$ $0.66, P<0.001)$. There was no significant relationship between $P_{0.1}$ and the decrease in TLCO, whereas EL and TLCO were significantly correlated $(r=0.45, P<0.05)$. The increase in $\mathrm{EL}_{\mathrm{L}}$ was significantly related to the shortening in TI $(r=0.55, P<0.01)$ (Fig. 6, upper panel), to the increase in $\mathrm{VT}_{\mathrm{BW}} / \mathrm{T}_{\mathrm{I}}(r=0.52, P<$ 


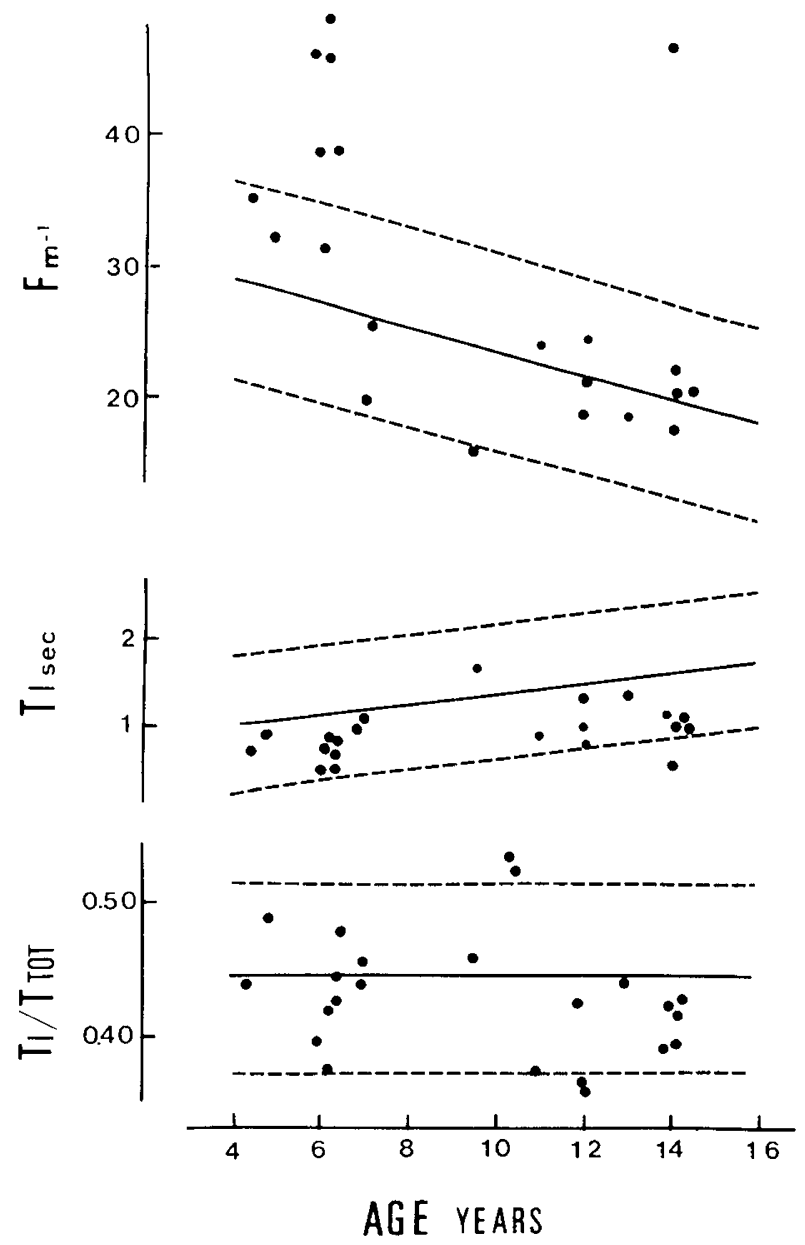

Fig. 1. Plots of respiratory frequency (f) in breath per min (upper panel), inspiratory time ( $\mathrm{TI}$ ) in second (middle panel), and the ratio of $\mathrm{TI}_{\mathrm{I}}$ to the total duration of the respiratory cycle (TI/Tтот)(lower panel) versus age in ILD children. Full and dotted lines indicate mean \pm 2 S.D. in healthy children (9), full circles are values in ILD children.

0.02 ) (Fig. 6, middle panel) and to the effective inspiratory impedance $(r=0.55, P<0.0$ l) (Fig. 6, lower panel). During the followup studies in cases $1,4,8,14$ (table 1 and 2) the changes in control of breathing variables were also correlated with the changes in lung mechanics and in gas exchange.

\section{DISCUSSION}

Breathing pattern and mouth occlusion pressure $\left(P_{0.1}\right)$ change with age, as we have previously shown (9). Thus children with respiratory disease have to compared to healthy children of the same age.

As in adults resting respiratory frequency, minute ventilation were increased in ILD children $(2,12,13,17)$. In our population V $\mathrm{T}$ was normal as Renzi (17) observed in ILD adults while Camus (2) reported a decreased $V r$. We found a significantly reduced $\mathrm{VT}_{\mathrm{BW}} / \mathrm{T}_{\mathrm{I}}$ because of a shortening in $\mathrm{T}_{1}$. The shortening in $\mathrm{T}_{1}$ was significantly related to the increase in lung elastance (EL) (Fig. 6, upper panel). TI was shorter than TE, thus the TI/TTOT ratio was significantly lowered. In contrast ${ }^{-I L D}$ adults have normal $\mathrm{TI} /$ TTOT ratio at rest $(2,17)$ and during $\mathrm{CO}$. breathing (3). A greater shortening in $\mathrm{Tr}$ in ILD children may reflect stronger afferent reflexes originating from lung (14) or chest wall (16) than in adults.

$P_{0.1}$ was significantly higher than predicted in our ILD children as reported in adults $(2,3,17,18) . P_{(0,1}$ depends on the neural drive and the advantage of the respiratory muscles as pressure generators (5).

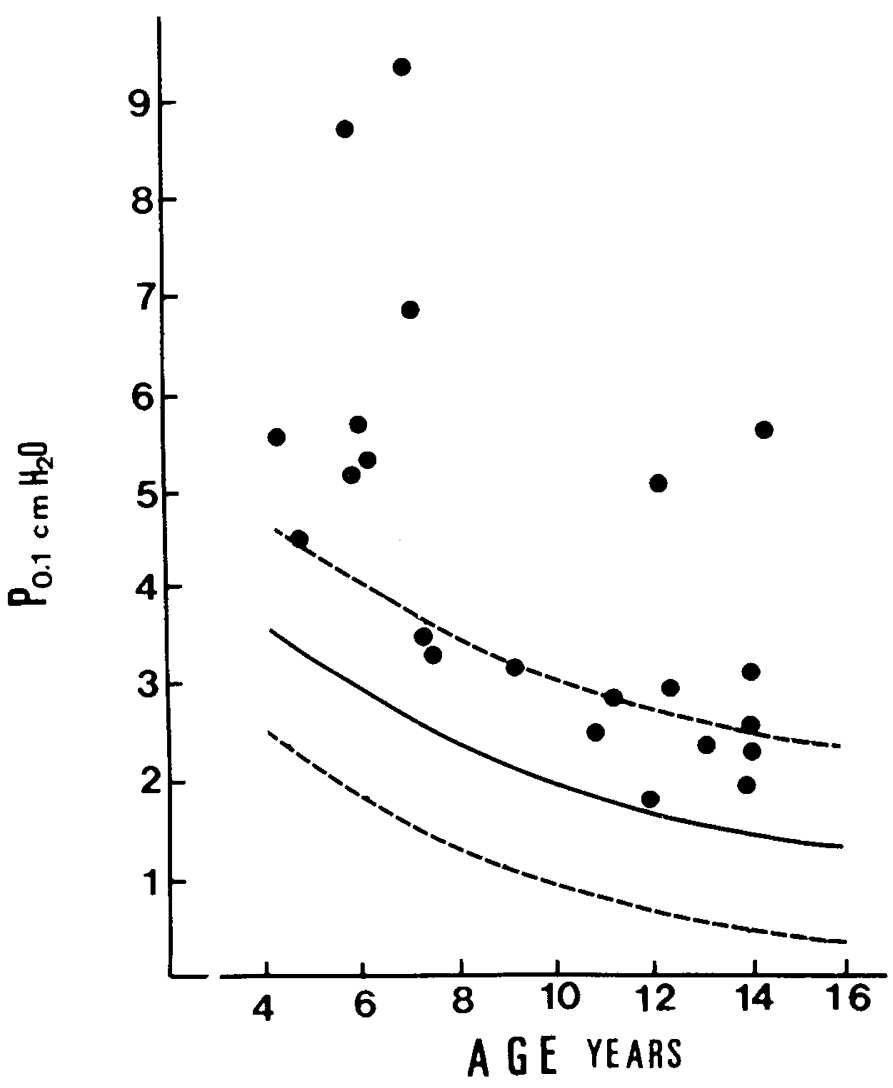

Fig. 2. Mouth occlusion pressure $\left(\mathrm{P}_{t .1}\right)$ and $\mathrm{cmH}_{2} \mathrm{O}$ plotted against age. Symbols as in Figure 1 .
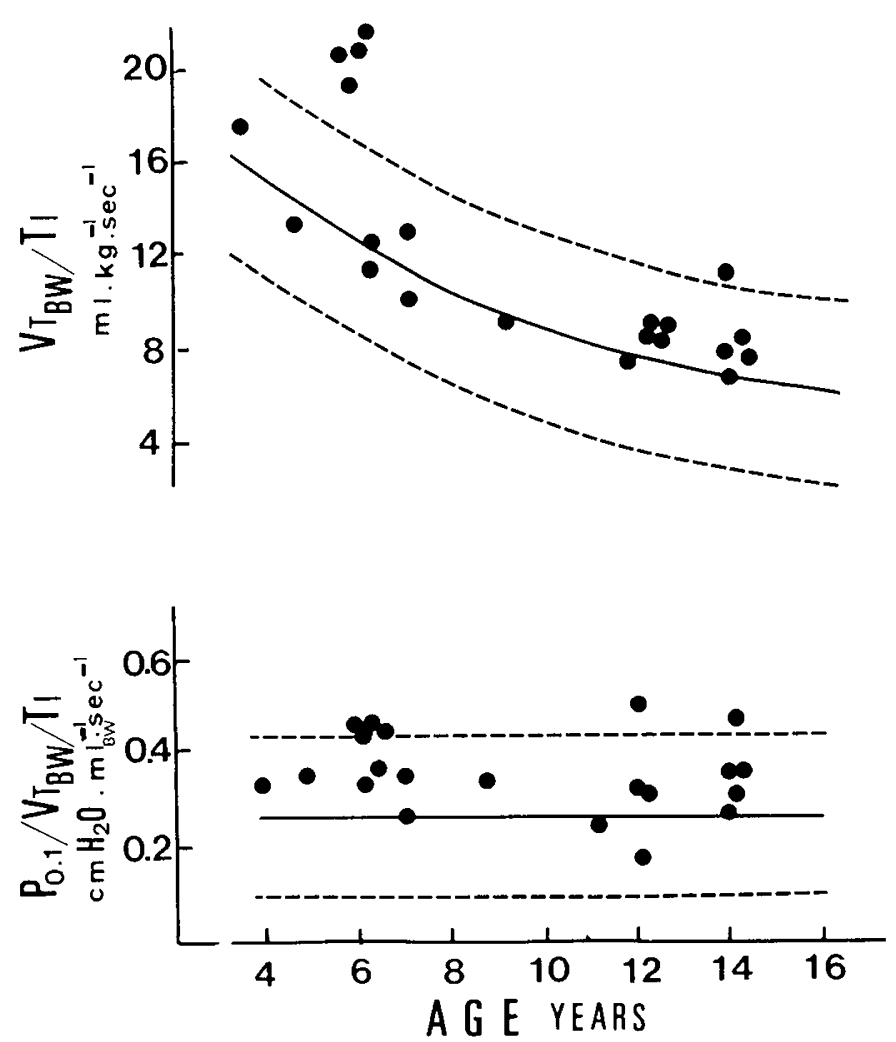

Fig. 3. Mean inspiratory flow $\left(\mathrm{VT}_{\mathrm{BW}} / \mathrm{Tr}\right)$ in $\mathrm{ml} \cdot \mathrm{kg}^{-1} \cdot \mathrm{sec}^{-1}$ (upper panel) and ratio of $\mathrm{P}_{0.1}$ to $\mathrm{VT}_{\mathrm{BW}} / \mathrm{TI}_{\mathrm{I}}$ (lower panel) plotted against age. Symbols as in Figure 1. 


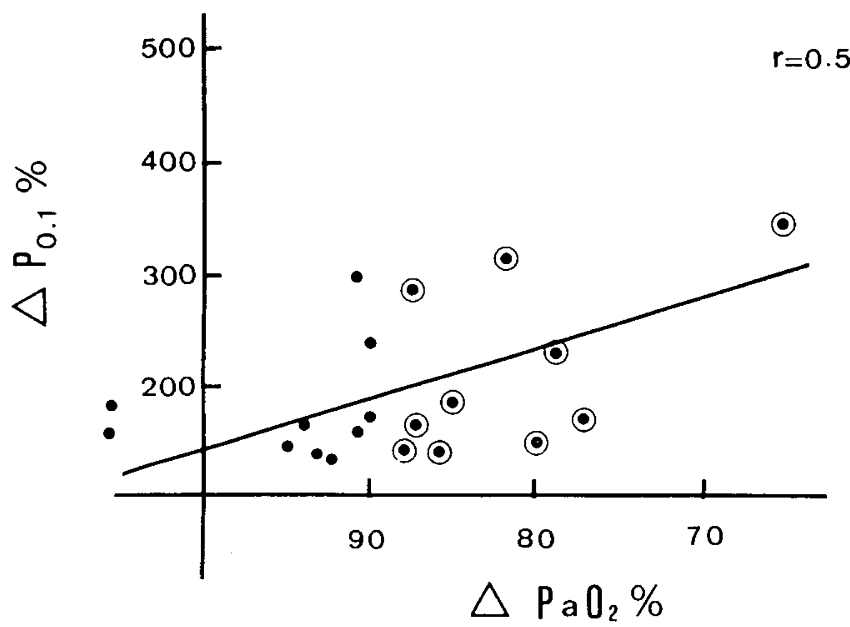

Fig. 4. Relationship between change in $\mathrm{PaO} .2$ and increase in $\mathrm{P}_{0.1}$ both expressed as \% of predicted values. Full circles indicate results of ILD children with $\mathrm{PaO}_{2}$ in the normal range, and double circles values in ILD children with PaOz, significantly reduced.

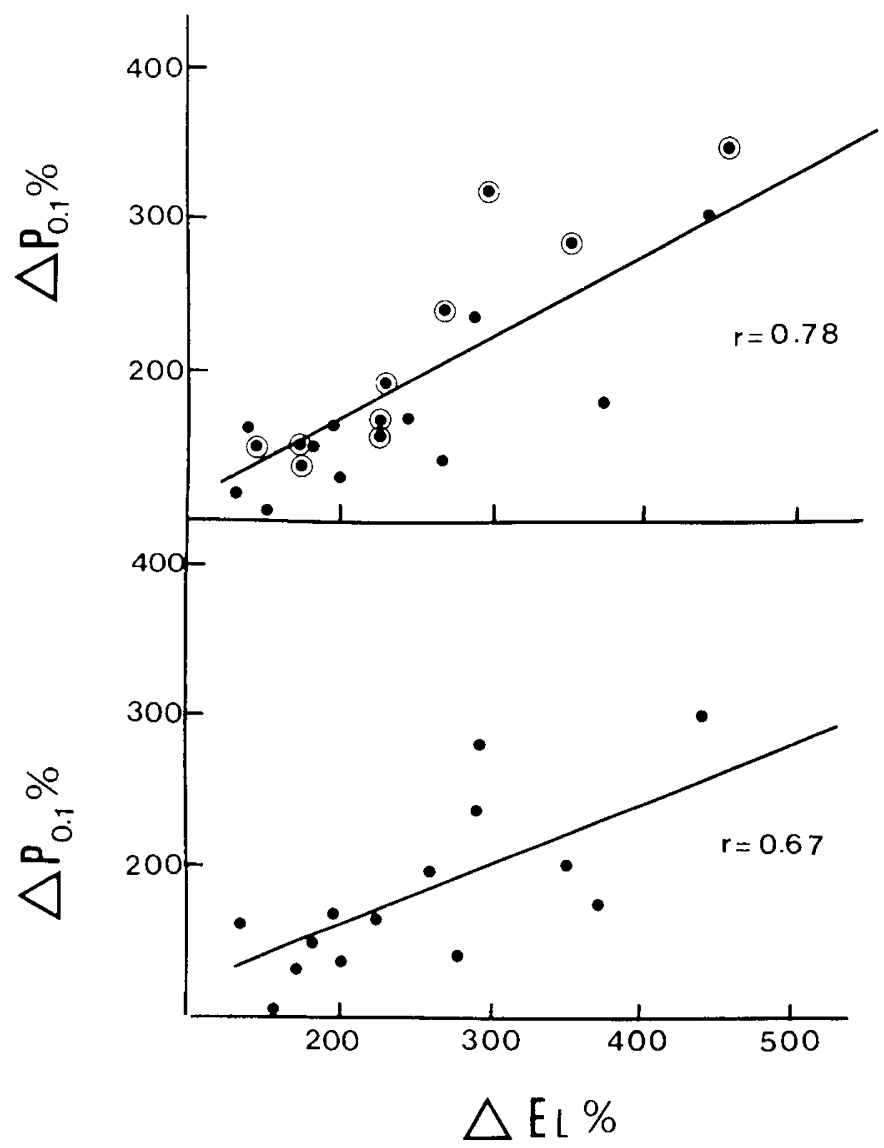

Fig. 5. Relationship between increase in lung elastance $\left(E_{L}\right)$ and in $P_{01.1}$, both expressed as \% of predicted values. In the upper panel results of the whole ILD group are given, in the lower panel only $P_{0.1}$ of patients with normal $\mathrm{PaO}_{2}$ and of four hypoxemic patients after $\mathrm{O}_{2}$ breathing are plotted versus the corresponding increase in El.. Symbols as in Figure 4.

A high $P_{0.1}$ could be attributed to change in the effectiveness of the inspiratory muscle force. In ILD adults muscle force and thoracic compliance were found to be not modified (4). Our children did not perform maximal static inspiratory efforts, so we do not know the values for their maximal static inspiratory pressures. But we have previously reported in ILD during child- hood a significant relationship between the decrease in lung volumes and in lung compliance (7), which suggested no change in thoracic compliance. On the other hand the inspiratory muscle action is affected by changes in the end-expiratory volume [functional residual capacity (FRC) (6)]. A decrease in FRC results in longer inspiratory muscle length, and hence promote an increased $P_{0.1}(5)$. Burki did not find any significant correlation between $P_{0.1}$ and change in FRC in healthy subjects, but Camus (2) in ILD adults observed an increase in $\mathrm{P}_{0.1}$ when FRC decreased. A decreased FRC was observed in several ILD children (Table 1); however, in spite of the possible influence of the reduced FRC in these cases, the higher $P_{0.1}$ probably reflects also a greater neural drive which may be related in part to gas exchange abnormalities and/or to changes in lung mechanics.

In ten cases, Pao. was significantly reduced (Fig. 4, double circles), only one patient had severe hypoxemia (case no. 4). A close relationship was observed between the changes in $\mathrm{PaO}_{2}$ and in $\mathrm{P}_{0.1}$ (Fig. 4), the lower was $\mathrm{PaO}_{2,}$, the higher was $\mathrm{P}_{0.1 .1}$. The results are in agreement with previous reports of increase in $P_{0,1}$ with hypoxia in healthy adults (11) and in hypoxemic children with chronic bronchial obstruction (8).

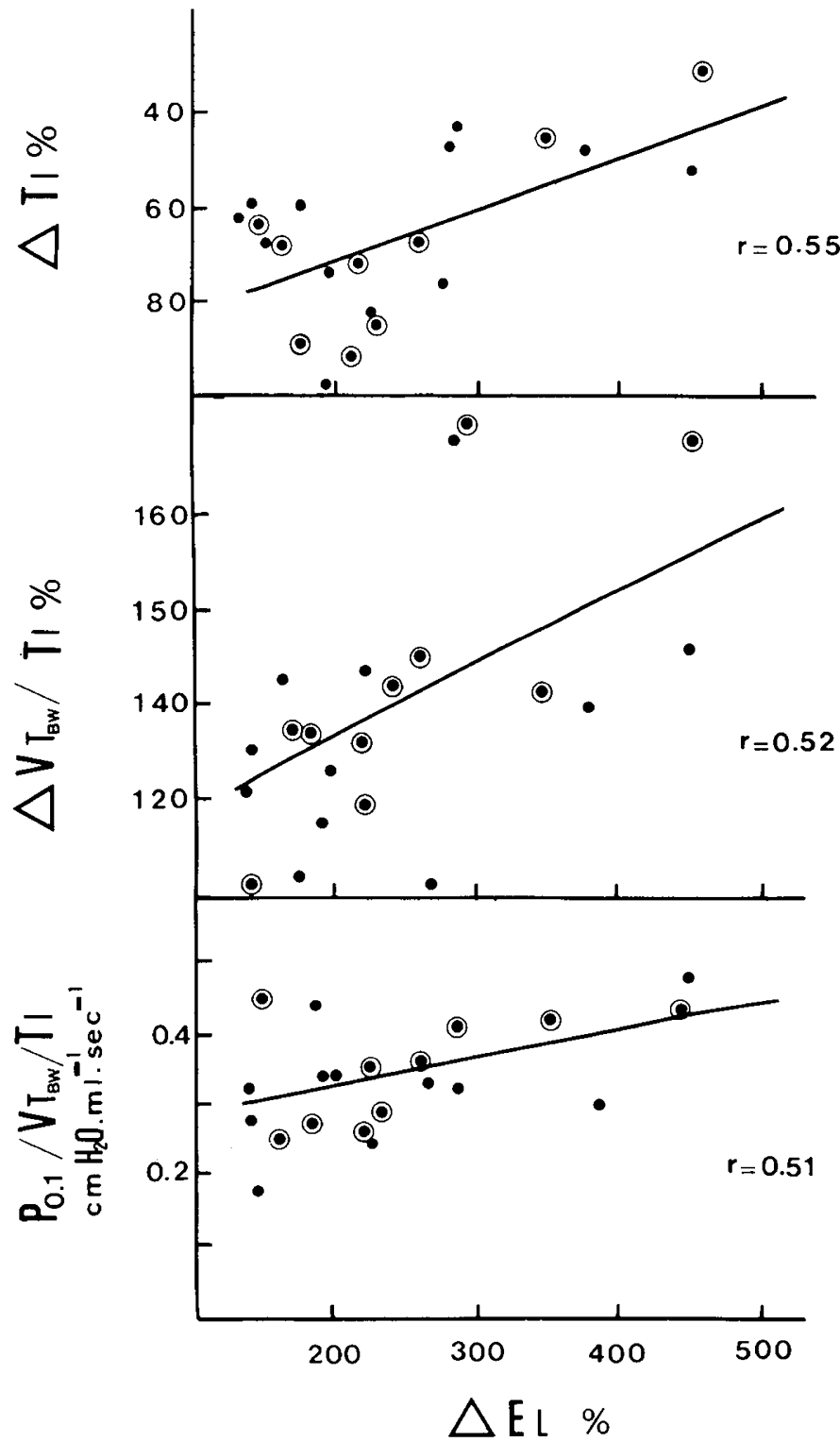

Fig. 6. Relationship between increase in $E_{L}$ and shortening in $T_{1}$ (upper panel), increase in mean inspiratory flow $\left(\mathrm{VT}_{\mathrm{BW}} / \mathrm{TI}\right)$ (middle panel) and effective inspiratory impedance $\left(\mathrm{P}_{0.1} / \mathrm{VT}_{\mathrm{BW}} / \mathrm{T}_{\mathrm{I}}\right)$ (lower panel). $\mathrm{EL}, \mathrm{TI}$, and $\mathrm{VT}_{\mathrm{BW}} / \mathrm{Tr}$ are expressed as \% of predicted values. Symbols as in Figure 4. 
If hypoxemia may partially explain the high $\mathrm{P}_{(0.1}$ in ILD, changes in lung mechanics must be also considered. RL of our patient was in the normal range (that is $100 \% \pm 50$ of predicted) except in case no. 7 (Table 1), thus afferent reflexes originating from central airways (14) probably were not involved in the increased neural drive. A decreased lung compliance and thus an increased lung elastance $\left(E_{L}\right)$ (Table 1 ) were present in all the cases. In five children dynamic and static $E_{L}$ were measured and found equal, in these cases increase in EL reflects the enhanced elastic load. In the others cases only dynamic EL was obtained. Increase in dynamic EL may reflect the enhanced elastic load; however, it may be due in part to a ventilatory asynchronism resulting from unequal changes in the calibre of the peripheral airways. In our population of ILD children increase in $E_{L}$ was significantly correlated with the increase in $P_{0.1}$ (Fig. 5, upper panel). In children with decreased $\mathrm{PaO}_{2}$ (double circles) (Fig. 5, upper panel), both increased chemical drive and elastic load are associated to explain high $P_{0.1}$. Thus, in order to suppress the effects of hypoxemia, we plotted the $P_{0.1}$ of the normoxemic patients and the $P_{0.1}$ of four hypoxemic patients obtained after $\mathrm{O}_{2}$ breathing versus the corresponding increase in lung elastance (Fig. 5, lower panel). In this way, the increase in $P_{0,1}$ was related only to the increase in $E_{L}$. The significant correlation $(r=0.68, P<0.01)$ suggests that increased EL enhances neural drive probably by way of afferent reflexes originating from the lungs $(12,14)$. The augmenting of the elastic load on $P_{0.1}$ was previously demonstrated in healthy (19) and in ILD adults at rest (17) and during exercise (20). Increased neural drive in response to elastic load is presumed vagally-mediated. In animals with experimentally induced ILD (15) and in humans (10), modification of breathing pattern was reported by blocking the vagus nerve; however, recently Savoy (18) did not observe any change in control of breathing after xylocaine inhalation in ILD adults.

ILD children had a greater effective inspiratory impedance than healthy children (Fig. 3, lower panel). The effective inspiratory impedance is the ratio between the rate of mouth pressure potentially available for inspiration $\left(\mathrm{P}_{0,1}\right)$ and the resulting flow $\left(\mathrm{VT}_{\mathrm{BW}} /\right.$ $\mathrm{T}_{1}$ ). In ILD children both $\mathrm{P}_{0.1}$ and $\mathrm{VT}_{\mathrm{BW}} / \mathrm{T}_{\mathrm{I}}$ were increased (Fig. 2 and 3, upper panel), but $\mathrm{VT}_{\mathrm{BW}} / \mathrm{T}_{\mathrm{I}}$ was not as much increased as $P_{0.1}$ because of the changes in lung mechanics. In fact the increase in the effective inspiratory impedance was significantly correlated with the increase in EL (Fig. 6, lower panel). Such relationship has been reported in ILD adults during $\mathrm{CO}_{2}$ breathing and during maximal exercise $(8,20)$.

We did not find any correlation between diffusion defect and increase in $P_{0.1}$. Thus, receptors located in the interstitium do not seem to be involved with changes in control of breathing in our ILD children.

We conclude that ILD in children is associated with increased neural drive which is related to hypoxemia and increased lung elastance.

\section{REFERENCES AND NOTES}

1. Burki, N. K.: The effects of changes in functional residual capacity with posture on mouth occlusion pressure and ventilatory pattern. Am. Rev. Resp. Dis.,
116: 895 (1977).

2. Camus, P. and Desmeules M.: Effets du volume pulmonaire sur le contrôle respiratoire dans les fibroses interstitielles diffuses. Canadian Lung Association 79th Meeting. Toronto p. 27 (1979).

3. Derenne. J. Ph.. Murciano. D.. Clergue. F.. Aubier, M., Fournier, M.. Daghfous, J.. and Pariente. R.: Control of breathing in diffuse pulmonary fibrosis. Am. Rev. Reps. Dis.. 17: 329 (1978).

4. DeTroyer, A. and Yernault, J. C.: Inspiratory muscle force in normal subjects and patients with interstitial lung disease. Thorax, 35: 92 (1980).

5. Eldridge. F. L.: Relationship between respiratory nerve and muscle activity and muscle force output. J. Appl. Physiol., 39: 567 (1975).

6. Eldridge. F. L. and Vaughn, K. Z.: Relationship of thoracic volume and airway occlusion pressure: muscular effects. J. Appl. Physiol.. 43: 312 (1977).

7. Gaultier, Cl.. Chaussain, M., Boule, M.. Buvry, A., Allaire, Y., Perret, L., and Girard. F.: Lung function in interstitial lung diseases in children. Bull. Europ. Physiopath. Resp., 16: 57 (1980).

8. Gaultier, Cl.. Perret. L., Boule, M., Grimfeld, A.. Baculard, A., and Girard, F.: Control of breathing in children with chronic obstruction pulmonary disease. Pro. Resp. Res. Karger, 17: 78 (1981).

9. Gaultier. Cl., Perret, L.. Boule, M., and Girard, F.: Occlusion pressure and breathing pattern in healthy children. Respir. Physiol., 46: 71 (1981).

10. Gutz. A.. Noble. M. I. and Eisele, J. E.. and Trenchard, D. W.: Experimental results of vagal block in cardiopulmonary disease. In Porter, R., Ed: Breathing: Hering-Breüer Century. Symposium. London. J and A. Churchill. pp 315-329 (1970).

11. Kelsen. S. G.. Altose. M. D.. Stanley, N. N., Levinson, R. S., Cherniack, N. S. and Fishman, A. P.: Effect of hypoxia on the pressure developed by inspiratory muscles during airway occlusion. J. Appl. Physiol., 40: 372 (1976).

12. Kornbluth. R. S. and Turino. G. M.: Respiratory control in diffuse interstitial lung disease and diseases of the pulmonary vasculature. Clinics in Chest Med., 1: 91 (1980)

13. Lourenço, R. V.. Turino, G. M., Davidson, L. A., and Fishman, A. P.: The regulation of ventilation in diffuse pulmonary fibrosis. Amer. J. Med., 38: 199 (1971).

14. Paintal, A.S.: Vagal sensory receptors and their reflex effects. Physiol. Rev.. 53: 159 (1973).

15. Phillipson. E. A., Murphy. E.. Kozar, L. F.. and Schultze, R. K.: Role of vagal stimuli in exercise ventilation in dogs with experimental pneumonitis. J. Appl. Physiol.. 39: 76 (1975).

16. Remmers, J. E.: Inhibition of inspiratory activity by intercostal muscle afferents. Respir. Physiol.. 10: 358 (1970).

17. Renzi, G.. Milic-Emili, J, and Grassino, A. E.: Control of breathing in patients with interstitial pulmonary fibrosis. Am. Rev. Resp. Dis.. I7: 384 (1978).

18. Savoy. J.. Dhingra. S., and Anthonisen. N. R.: Breathing pattern regulation in fibrotic lung disease. Am. Rev. Resp. Dis., 123: 184 (1981).

19. Shekleton. M., Lopata. M., Evanich. M. J.. Lourenço. R. V.: Effect of elastic loading on mouth occlusion pressure during $\mathrm{Co}_{2}$ rebreathing in man. Am. Rev. Reps. Dis.. 114: 341 (1976).

20. VanMeerhaeghe. A., Scano, G., Sergysels, R.. Bran. M., DeCoster, A.: Respiratory drive and ventilatory pattern during exercise in interstitial lung disease. Bull. Europ. Physiopath. Resp., 17: 15 (1981).

21. Whitelaw. W. A.. Derenne. J.Ph., and Milic-Emili. J.: Occlusion pressure as a measure of respiratory center output in conscious man. Respir. Physiol., 23: 181 (1975).

22. Part of this work was presented at the FASEB meeting of the American Physiological Society - Atlanta. 1981. and at the European Paediatric Respiratory Society-Berne, 1981.

23. The authors wish to express their gratitude to Dr J. Milic-Emili for his advice and criticism, and to $\mathrm{H}$. Pham-Thi and M. C. Miesch for their technical assistance.

24. Requests for reprints should be addressed to: Dr. Cl. Gaultier, Laboratory of Physiology, Hospital Trousseau, 26 Avenue du Dr. Cl. Gaultier, Paris 75012, France.

25. This work was supported by the "Contrat Jeunes Equipes" Faculte Saint-Antoine. Université Paris VI.

26. Received for publication July $27,1981$.

27. Accepted for publication October 20.1981. 